\title{
Vibrational spectroscopic characterization of the sulphate mineral khademite $\mathrm{Al}\left(\mathrm{SO}_{4}\right) \mathrm{F} \cdot 5\left(\mathrm{H}_{2} \mathrm{O}\right)$
}

\author{
Ray L. Frost ${ }^{\mathrm{a}, *}$, Ricardo Scholz ${ }^{\mathrm{b}}$, Andrés López ${ }^{\mathrm{a}}$, Yunfei Xi ${ }^{\mathrm{a}}$

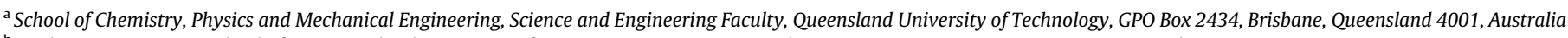 \\ ${ }^{\mathrm{b}}$ Geology Department, School of Mines, Federal University of Ouro Preto, Campus Morro do Cruzeiro, Ouro Preto, MG 35,400-00, Brazil
}

\section{H I G H L I G H T S}

- We have studied the sulphate mineral khademite $\mathrm{Al}\left(\mathrm{SO}_{4}\right) \mathrm{F} \cdot 5\left(\mathrm{H}_{2} \mathrm{O}\right)$.

- Using vibrational spectroscopy.

- The observation of multiple water stretching vibrations gives credence to the non-equivalence of water units.

- Vibrational spectroscopy enables an assessment of the structure of khademite.

\section{A R T I C L E I N F O}

\section{Article history:}

Received 30 May 2013

Received in revised form 1 July 2013

Accepted 16 July 2013

Available online 24 July 2013

\section{Keywords:}

Khademite

Sulphate

Raman spectroscopy

Infrared spectroscopy

\section{G R A P H I C A L A B S T R A C T}

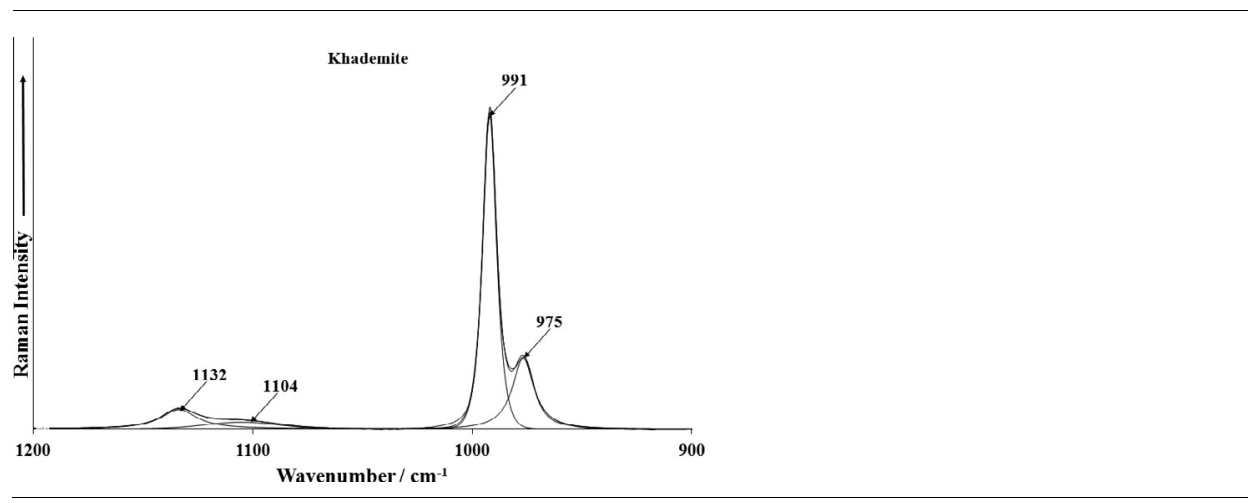

\begin{abstract}
A B S T R A C T
Vibrational spectroscopy has been used to characterize the sulphate mineral khademite $\mathrm{Al}(\mathrm{SO} 4) \mathrm{F} \cdot 5(\mathrm{H} 2 \mathrm{O})$. Raman band at $991 \mathrm{~cm}-1$ with a shoulder at $975 \mathrm{~cm}-1$ is assigned to the $v 1$ (SO4)2 - symmetric stretching mode. The observation of two symmetric stretching modes suggests that the sulphate units are not equivalent. Two low intensity Raman bands at 1104 and $1132 \mathrm{~cm}-1$ are assigned to the v3 (SO4)2- antisymmetric stretching mode. The broad Raman band at $618 \mathrm{~cm}-1$ is assigned to the $v 4$ (SO4) $2-$ bending modes. Raman bands at 455, 505 and $534 \mathrm{~cm}-1$ are attributable to the doubly degenerate v2 (SO4)2bending modes. Raman bands at 2991,3146 and $3380 \mathrm{~cm}-1$ are assigned to the $\mathrm{OH}$ stretching bands of water. Five infrared bands are noted at 2458, 2896, 3203, 3348 and $3489 \mathrm{~cm}-1$ are also due to water stretching bands. The observation of multiple water stretching vibrations gives credence to the nonequivalence of water units in the khademite structure. Vibrational spectroscopy enables an assessment of the structure of khademite.
\end{abstract}

(c) 2013 Elsevier B.V. All rights reserved.

\section{Introduction}

The mineral khademite is a fluorinated hydrated sulphate of aluminium of formula $\mathrm{Al}\left(\mathrm{SO}_{4}\right) \mathrm{F} \cdot 5\left(\mathrm{H}_{2} \mathrm{O}\right)[1,2]$. It is rarely formed in the oxidized zone of hydrothermal base-metal deposits [3]. This mineral is known from a number of places in Australia, including

\footnotetext{
* Corresponding author. Tel.: +61 73138 2407; fax: +61 731381804 .

E-mail address: r.frost@qut.edu.au (R.L. Frost).
}

the Kintore open Cut Mine at Broken Hill, NSW, Australia. The mineral is associated with other fluorinated sulphates namely wilcoxite $\operatorname{MgAl}\left(\mathrm{SO}_{4}\right)_{2} \mathrm{~F} \cdot 18\left(\mathrm{H}_{2} \mathrm{O}\right)$, lannonite $\mathrm{HCa}_{4} \mathrm{Mg}_{2} \mathrm{Al}_{4}\left(\mathrm{SO}_{4}\right)_{8} \mathrm{~F}_{9} \cdot 32\left(\mathrm{H}_{2} \mathrm{O}\right)$ [4].

This sulphate mineral is found in many parts of the world including from Saghand, Yazd, Iran; at the Rammelsberg mine, near Goslar, Harz Mountains, Germany; in the Cetine mine, $20 \mathrm{~km}$ southwest of Siena, Tuscany, Italy; from the Schoeller mine, Libưsin, near Kladno, Czech Republic and in the Lone Pine mine, Wilcox district, near Silver City, Catron Co., New Mexico, USA. Khademite $[4,5]$ is associated with copiapite, amarantite, 
parabutlerite, butlerite, jarosite (Saghand, Iran); wilcoxite, lannonite, gypsum (Lone Pine mine, New Mexico, USA). The mineral type locality is from Saghand, Iran.

The mineral [3] is orthorhombic with Point Group: $2 / \mathrm{m} \mathrm{2} / \mathrm{m} \mathrm{2} / \mathrm{m}$. The cell data is Space Group: Pcab. $a=11.181(4), b=13.048(5)$, $c=10.885(4)$, with $Z=8$. According to Bachet et al. [3] the structure consists of discrete $\mathrm{SO}_{4}$ tetrahedra, $\mathrm{Al}(\mathrm{Ow}) 6$ and $\mathrm{Al}(\mathrm{Ow}) 4 \mathrm{~F} 2$ octahedra connected by a network of $\mathrm{H}$ bonds. Al atoms are in special positions $4(a)$ and $4(b)$ and the corresponding octahedra form sheets parallel to (100); they alternate with $\mathrm{SO}_{4}$ tetrahedra.

This paper is a part of systematic studies of vibrational spectra of minerals of secondary origin in the oxide supergene zone. In this work, we attribute bands at various wavenumbers to vibrational modes of khademite using Raman spectroscopy complemented with infrared spectroscopy and relate the spectra to the structure of the mineral.

\section{Experimental}

\section{Samples description and preparation}

The khademite sample studied in this work was collected from Kladno Mine, Central Bohemia Region, Czech Republic [6]. The mineral occurs as efflorescence covering the weathered rock. The individual crystals show prismatic habitus. The sample was incorporated into the collection of the Geology Department of the Federal University of Ouro Preto, Minas Gerais, Brazil, with sample code SAB-079. The sample was gently crushed and the associated minerals were removed under a stereomicroscope Leica MZ4.

\section{Raman microprobe spectroscopy}

Crystals of khademite were placed on a polished metal surface on the stage of an Olympus BHSM microscope, which is equipped with $10 \times, 20 \times$, and $50 \times$ objectives. The microscope is part of a Renishaw 1000 Raman microscope system, which also includes a monochromator, a filter system and a CCD detector (1024 pixels). The Raman spectra were excited by a Spectra-Physics model 127 He-Ne laser producing highly polarized light at $633 \mathrm{~nm}$ and collected at a nominal resolution of $2 \mathrm{~cm}^{-1}$ and a precision of $\pm 1 \mathrm{~cm}^{-1}$ in the range between 200 and $4000 \mathrm{~cm}^{-1}$. Repeated acquisitions on the crystals using the highest magnification $(50 \times)$ were accumulated to improve the signal to noise of the spectra. Raman Spectra were calibrated using the $520.5 \mathrm{~cm}^{-1}$ line of a silicon wafer. The Raman spectrum of at least 10 crystals was collected to ensure the consistency of the spectra.

A spectrum of khademite is given in the RRUFF data base at http://rruff.info/Khademite.

This spectrum suffers from a lack of signal. No band assignments are provided and no assessment of the $\mathrm{OH}$ stretching region is shown. The downloaded spectrum is reported in the Supplementary information as Fig. S1.

\section{Infrared spectroscopy}

Infrared spectra were obtained using a Nicolet Nexus 870 FTIR spectrometer with a smart endurance single bounce diamond ATR cell. Spectra over the $4000-525 \mathrm{~cm}^{-1}$ range were obtained by the co-addition of 128 scans with a resolution of $4 \mathrm{~cm}^{-1}$ and a mirror velocity of $0.6329 \mathrm{~cm} / \mathrm{s}$. Spectra were co-added to improve the signal to noise ratio. The infrared spectra are given in the Supplementary information.

Spectral manipulation such as baseline correction/adjustment and smoothing were performed using the Spectracalc software package GRAMS (Galactic Industries Corporation, NH, USA). Band component analysis was undertaken using the Jandel 'Peakfit' software package that enabled the type of fitting function to be selected and allows specific parameters to be fixed or varied accordingly. Band fitting was done using a Lorentzian-Gaussian cross-product function with the minimum number of component bands used for the fitting process. The Gaussian-Lorentzian ratio was maintained at values greater than 0.7 and fitting was undertaken until reproducible results were obtained with squared correlations of $r^{2}$ greater than 0.995 .

\section{Results and discussion}

\section{Vibrational Spectroscopy}

The mineral khademite contains both sulphate and fluoride anions, and therefore, the presence of these anions may be observed using vibrational spectroscopy. Certainly any oxyanion may be observed. It should be noted that the fluoride anion and the hydroxyl anion are about equal in size and in nature one may repalce the other in mineral structures. As the structure and formula of khademite was researched, there was considerable arguement about its true formula.

The fluoride anion is much more difficult to detect using vibrational spectroscopy. A good starting point to study the position of the expected bands and to observe where the bands occur in aqueous solutions and then to observe the position of the bands resulting from the vibrational spectroscopy of minerals containing the individual anions. In aqueous systems, the sulphate anion is of $\mathrm{Td}$ symmetry and has symmetric stretching mode $\left(v_{1}\right)$ at $981 \mathrm{~cm}^{-1}$, the antisymmetric stretching mode $\left(v_{3}\right)$ at $1104 \mathrm{~cm}^{-1}$, the symmetric bending mode $\left(v_{2}\right)$ at $451 \mathrm{~cm}^{-1}$ and the $v_{4}$ mode at $613 \mathrm{~cm}^{-1}$ [5]. In aqueous systems, Raman spectra of phosphate oxyanions show a symmetric stretching mode $\left(v_{1}\right)$ at $938 \mathrm{~cm}^{-1}$, the antisymmetric stretching mode $\left(v_{3}\right)$ at $1017 \mathrm{~cm}^{-1}$, the symmetric bending mode $\left(v_{2}\right)$ at $420 \mathrm{~cm}^{-1}$ and the $v_{4}$ mode at $567 \mathrm{~cm}^{-1}$ [5].

S.D. Ross in Farmer's treatise [7] reported the infrared spectra of the jarosite-alunite minerals (Table 18.IX page 433). This table compares the infrared spectra of minerals from the alunite-jarosite supergroups. Ross reported infrared bands for sulphate containing alunite at $1030 \mathrm{~cm}^{-1}\left(v_{1}\right), 475 \mathrm{~cm}^{-1}\left(v_{2}\right), 1086,1170 \mathrm{~cm}^{-1}\left(v_{3}\right)$, $605,632 \mathrm{~cm}^{-1}\left(v_{4}\right) . \mathrm{OH}$ vibrations were reported at 3485 and $505,780,802 \mathrm{~cm}^{-1}$ attributed to the stretching and bending of the $\mathrm{OH}$ units. Infrared bands for jarosite $1018,1028 \mathrm{~cm}^{-1}\left(v_{1}\right)$, $482 \mathrm{~cm}^{-1}\left(v_{2}\right), 1100,1190 \mathrm{~cm}^{-1}\left(v_{3}\right), 638,685 \mathrm{~cm}^{-1}\left(v_{4}\right)$. OH vibrations for jarosite were reported at 3260, 3355, 3430 and $512,790 \mathrm{~cm}^{-1}$ attributed to the stretching and bending of the $\mathrm{OH}$ units. Raman spectra of these minerals have also been published [8-11]. These results serve to show the positions of the bands which may be assigned to sulphate and phosphate.

\section{Vibrational spectroscopy}

The Raman spectrum of khademite $\mathrm{Al}\left(\mathrm{SO}_{4}\right) \mathrm{F} \cdot 5\left(\mathrm{H}_{2} \mathrm{O}\right)$ over the $100-4000 \mathrm{~cm}^{-1}$ spectral range is illustrated in Fig. 1a. This spectrum shows the position and relative intensities of the Raman bands. It is noteworthy that there are large parts of the spectrum where little or no intensity is observed and therefore the spectrum is subdivided into sections based upon the type of vibration being studied. The infrared spectrum of khademite over the 500$4000 \mathrm{~cm}^{-1}$ spectral range is reported in Fig. 1b. This spectrum shows the position and relative intensity of the infrared bands. A comparison between the Raman and infrared spectra of khademite may be achieved. 


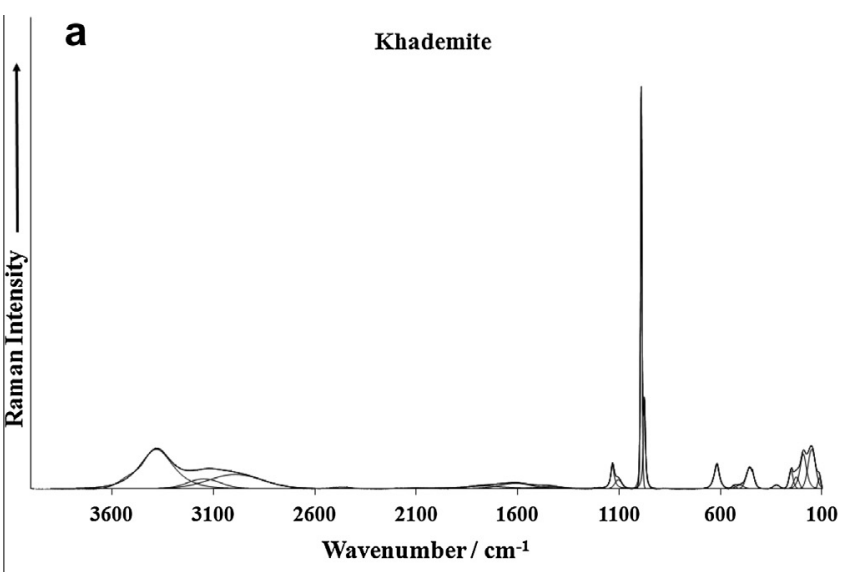

b

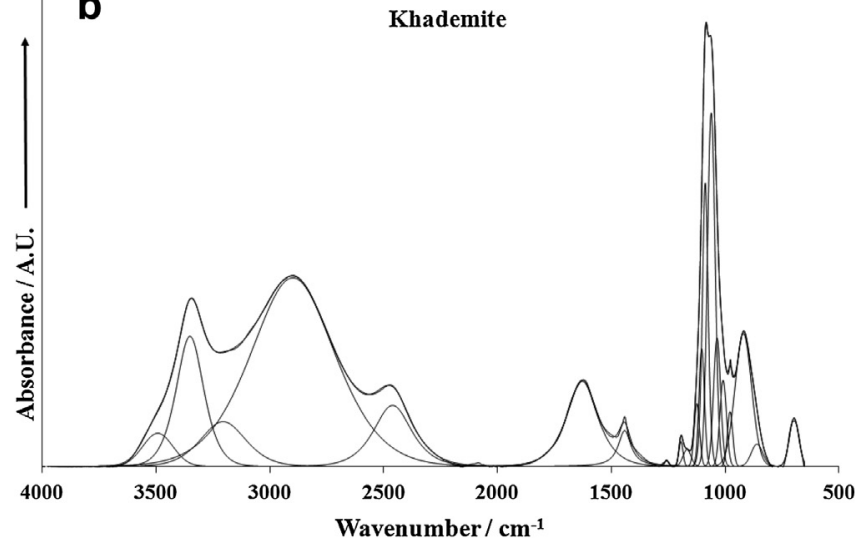

Fig. 1. (a) Raman spectrum of khademite over the $100-4000 \mathrm{~cm}^{-1}$ spectral range. (b) Infrared spectrum of khademite over the $500-4000 \mathrm{~cm}^{-1}$ spectral range.

The Raman spectrum of khademite in the $900-1200 \mathrm{~cm}^{-1}$ spectral range is shown in Fig. 2a. An intense Raman band at $991 \mathrm{~cm}^{-1}$ is assigned to the $v_{1}\left(\mathrm{SO}_{4}\right)^{2-}$ symmetric stretching mode. A second band is observed at $975 \mathrm{~cm}^{-1}$ and may also be attributed to this vibrational mode. It is noted that in the Raman spectrum on the RRUFF data base http://rruff.info/Khademite shows two strong sharp bands at around 981 and $990 \mathrm{~cm}^{-1}$.

The observation of two symmetric stretching modes suggests that the sulphate units are not equivalent. Perhaps, one sulphate unit is associated with the fluoride anion. Two low intensity Raman bands at 1104 and $1132 \mathrm{~cm}^{-1}$ are assigned to the $v_{3}\left(\mathrm{SO}_{4}\right)^{2-}$ antisymmetric stretching mode. In the Raman spectrum of khademite from the RRUFF data base, two strong Raman bands are noted at 1151 and $1176 \mathrm{~cm}^{-1}$ which are attributed to this antisymmetric stretching mode.

The infrared spectrum over the 500 to $1300 \mathrm{~cm}^{-1}$ spectral range is reported in Fig. 2b. The spectrum shows a complex set of overlapping bands, The most intense bands found at 1058 and $1084 \mathrm{~cm}^{-1}$ are attributed to the $v_{3}\left(\mathrm{SO}_{4}\right)^{2-}$ antisymmetric stretching mode. Other infrared bands at 1100, 1121, 1165 and $1181 \mathrm{~cm}^{-1}$ may also be attributed to this vibration. The two infrared bands at 975 and $1005 \mathrm{~cm}^{-1}$ may be attributed to the $v_{1}$ $\left(\mathrm{SO}_{4}\right)^{2-}$ symmetric stretching mode. It is thought that the infrared band at $917 \mathrm{~cm}^{-1}$ is associated with water and may be attributed to the water librational mode.

The Raman spectrum of khademite in the 300 to $800 \mathrm{~cm}^{-1} \mathrm{spec}-$ tral range and in the 100 to $300 \mathrm{~cm}^{-1}$ spectral range is reported in Fig. 3. The broad Raman band at $618 \mathrm{~cm}^{-1}$ which may be composed of multiple overlapping bands is assigned to the $v_{4}\left(\mathrm{SO}_{4}\right)^{2-}$ bending
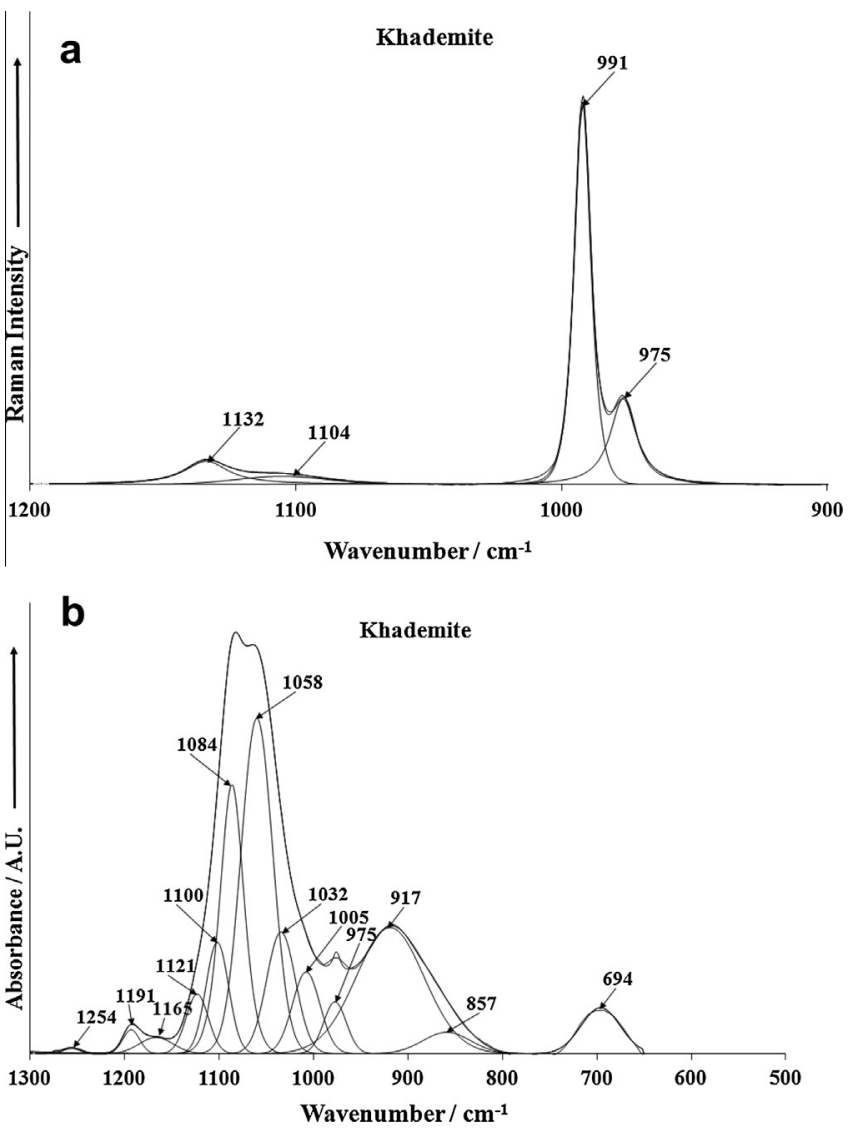

Fig. 2. (a) Raman spectrum of khademite over the $800-1400 \mathrm{~cm}^{-1}$ spectral range. (b) Infrared spectrum of khademite over the $500-1300 \mathrm{~cm}^{-1}$ spectral range.

modes. In the RRUFF spectrum, an intense band is observed at exactly this position. In this RRUFF spectrum, a band is noted at $823 \mathrm{~cm}^{-1}$ which was not detected in this work. The Raman bands at 455,505 and $534 \mathrm{~cm}^{-1}$ are attributable to the doubly degenerate $v_{2}\left(\mathrm{SO}_{4}\right)^{2-}$ bending modes. The RRUFF spectrum of khademite suffers from a lack of signal; nevertheless a band may be observed at $441 \mathrm{~cm}^{-1}$ with other bands observed on the higher wavenumber side of this band.

It is thought that the Raman band at $324 \mathrm{~cm}^{-1}$ is due to the AlO stretching vibration. The series of overlapping bands in Fig. $3 \mathrm{~b}$ are simply described as lattice vibrations.

The Raman spectrum in the $2600-3800 \mathrm{~cm}^{-1}$ spectral range is reported in Fig. 4a. The infrared spectrum over the 2000$3800 \mathrm{~cm}^{-1}$ spectral range is shown in Fig. 4b. The Raman bands at 2991,3146 and $3380 \mathrm{~cm}^{-1}$ are assigned to the $\mathrm{OH}$ stretching bands of water. Five infrared bands are noted at 2458, 2896, 3203,3348 and $3489 \mathrm{~cm}^{-1}$ are also due to water stretching bands. The observation of multiple water stretching vibrations gives credence to the non-equivalence of water units in the khademite structure. The position of the bands at quite relatively low wavenumber positions (e.g. 2458, 2896) indicates very strong hydrogen bonding in the khademite structure.

The Raman spectrum of khademite in the $1300-1900 \mathrm{~cm}^{-1}$ is reported in Fig. 5a. The spectrum suffers from a lack of signal, nevertheless a band may be observed at $1609 \mathrm{~cm}^{-1}$ and is ascribed to the water bending mode. The infrared spectrum of khademite over the $1300-2000 \mathrm{~cm}^{-1}$ spectral range is shown in Fig. 5b. A broad band at $1625 \mathrm{~cm}^{-1}$ is noted and assigned to the water bending mode. Another band is seen at $1439 \mathrm{~cm}^{-1}$. It is not known what this band may be assigned. 

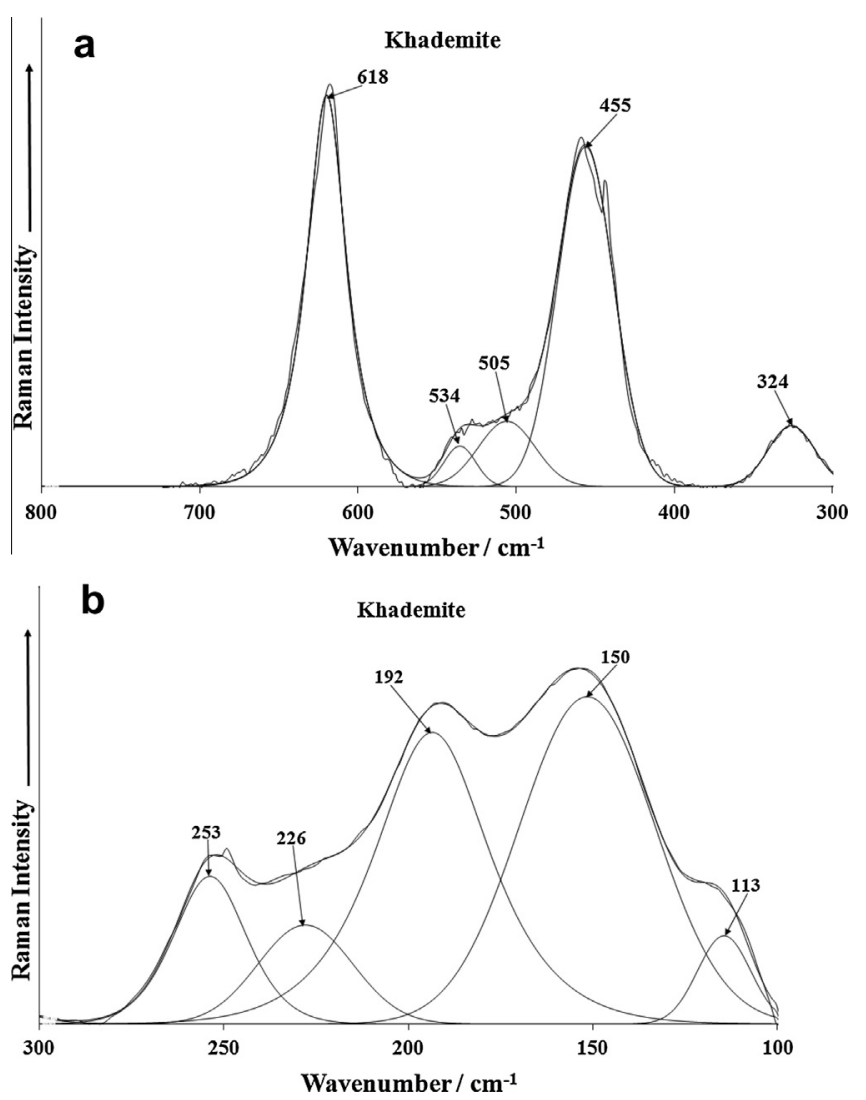

Fig. 3. (a) Raman spectrum of khademite over the $300-800 \mathrm{~cm}^{-1}$ spectral range. (b) Raman spectrum of khademite over the $100-300 \mathrm{~cm}^{-1}$ spectral range.
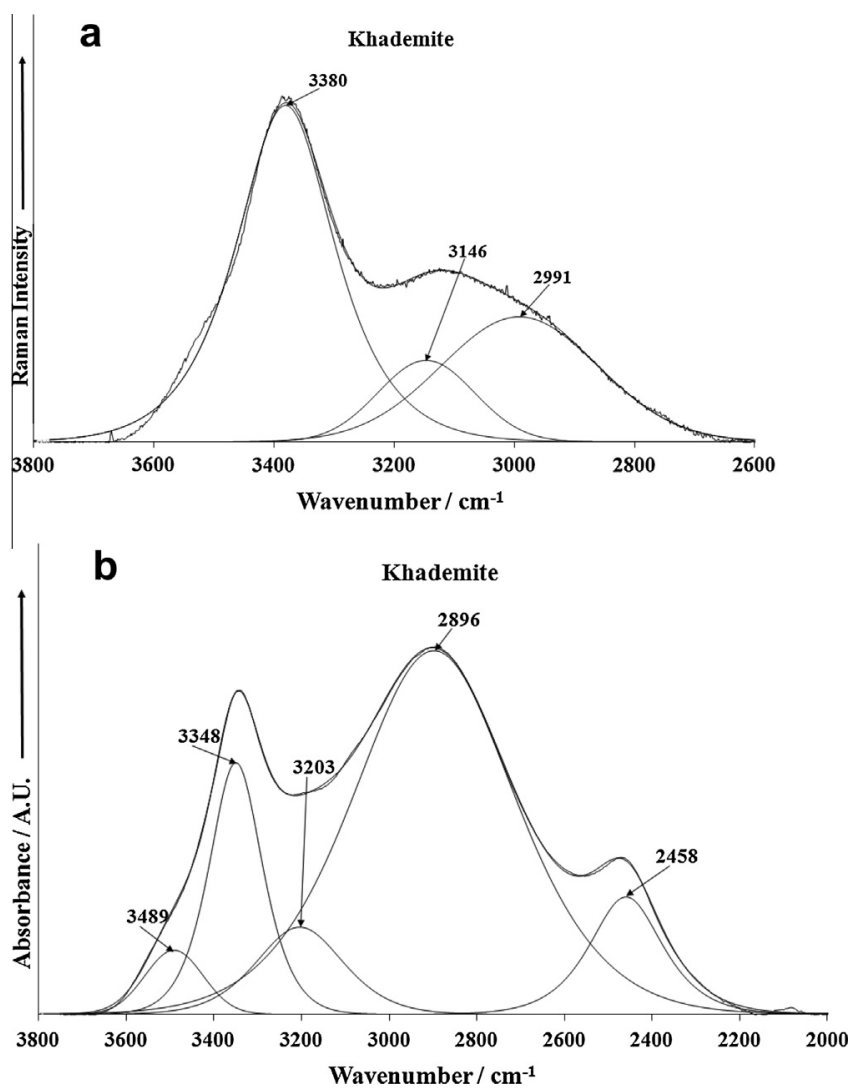

Fig. 4. (a) Raman spectrum of khademite over the $2600-4000 \mathrm{~cm}^{-1}$ spectral range. (b) Infrared spectrum of khademite over the $2600-4000 \mathrm{~cm}^{-1}$ spectral range.

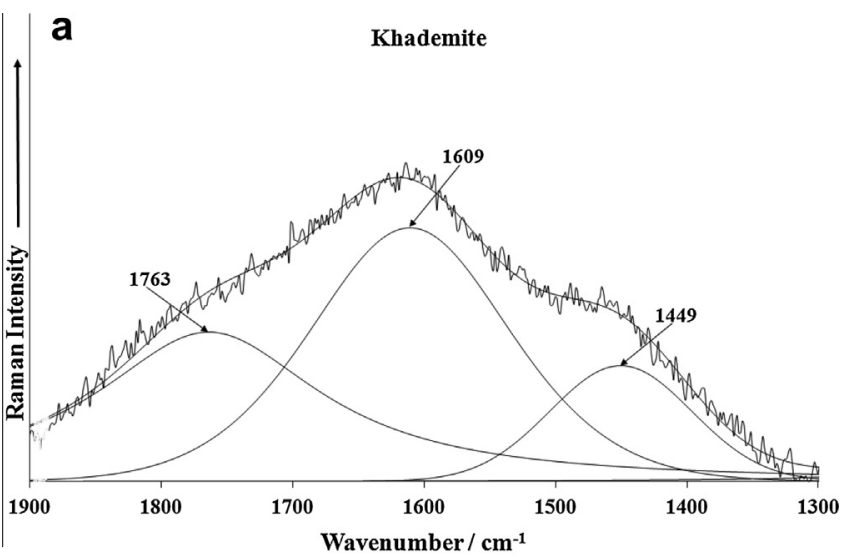

b

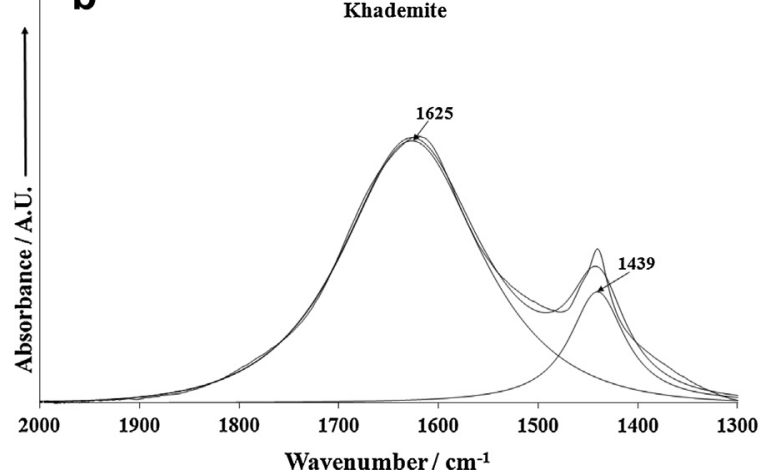

Fig. 5. (a) Raman spectrum of khademite over the $1300-1800 \mathrm{~cm}^{-1}$ spectral range. (b) Infrared spectrum of khademite over the $1300-1800 \mathrm{~cm}^{-1}$ spectral range.

\section{Conclusions}

A combination of Raman spectroscopy at ambient temperature complimented with infrared spectroscopy has been used to characterise the sulphate mineral known as khademite $\mathrm{Al}\left(\mathrm{SO}_{4}\right) \mathrm{F} \cdot 5\left(\mathrm{H}_{2} \mathrm{O}\right)$ originating from Kladno Mine, Central Bohemia Region, Czech Republic. Khademite is one of a very few fluorinated sulphate minerals including wilcoxite $\mathrm{MgAl}\left(\mathrm{SO}_{4}\right)_{2} \mathrm{~F} \cdot 18\left(\mathrm{H}_{2} \mathrm{O}\right)$, lannonite $\mathrm{HCa}_{4}$ $\mathrm{Mg}_{2} \mathrm{Al}_{4}\left(\mathrm{SO}_{4}\right)_{8} \mathrm{~F}_{9} \cdot 32\left(\mathrm{H}_{2} \mathrm{O}\right)$. Multiple symmetric stretching modes are observed and support the concept of the non-equivalent sulphate units in the khademite structure. The observation of multiple water stretching vibrations gives credence to the non-equivalence of water units in the khademite structure. The position of the bands at quite relatively low wavenumber positions (e.g. 2458, 2896) indicates very strong hydrogen bonding in the khademite structure.

\section{Acknowledgments}

The financial and infra-structure support of the Discipline of Nanotechnology and Molecular Science, Science and Engineering Faculty of the Queensland University of Technology, is gratefully acknowledged. The Australian Research Council (ARC) is thanked for funding the instrumentation. The authors would like to acknowledge the Center of Microscopy at the Universidade Federal de Minas Gerais (http://www.microscopia.ufmg.br) for providing the equipment and technical support for experiments involving electron microscopy. R. Scholz thanks to CNPq - Conselho Nacional de Desenvolvimento Científico e Tecnológico (Grant No. 306287/ 2012-9). 


\section{Appendix A. Supplementary material}

Supplementary data associated with this article can be found, in the online version, at http://dx.doi.org/10.1016/j.saa.2013.07.020.

\section{References}

[1] P. Bariand, J.P. Berthelon, F. Cesbron, M. Sadrzadeh, Compt. Rend. 277 (1973) 1585-1588.

[2] P. Bariand, F. Cesbron, J.P. Berthelon, Memoire Hors Soc. Geol. Fr. 8 (1977) 7785.

[3] B. Bachet, F. Cesbron, R. Chevalier, Bull. Min. 104 (1981) 19-22.
[4] S.A. Williams, F.P. Cesbron, Min. Mag. 47 (1983) 37-40.

[5] F.P. Cesbron, P. Bayliss, Min. Mag. 52 (1988) 133-134.

[6] V. Zacek, S. Oplustil, A. Mayova, F.R. Meyer, Tsch. Republik. Min. 6 (1995) 1330.

[7] V.C. Farmer, Mineralogical Society Monograph 4: The Infrared Spectra of Minerals, London, 1974.

[8] R.L. Frost, R.-A. Wills, M.L. Weier, W. Martens, S. Mills, Spectrochim. Acta A63 (2006) 1-8.

[9] R.L. Frost, R.-A. Wills, M.L. Weier, W. Martens, J. Raman Spectrosc. 36 (2005) 435-444.

[10] R.L. Frost, D.L. Wain, Spectrochim. Acta 71 (2008) 490-495.

[11] R.L. Frost, R.-A. Wills, M.L. Weier, W. Martens, J.T. Kloprogge, J. Mol. Struct. 785 (2006) 123-132. 